\title{
Leveraging Language: \\ Preliminary evidence from a language-based intervention at the University of Cape Town
}

\author{
Emma Whitelaw, Samantha Filby and Tessa Dowling \\ University of Cape Town, South Africa \\ Corresponding Author: emma.whitelaw@uct.ac.za
}

(Submitted: 23 October 2019; Accepted: 11 December 2019)

\begin{abstract}
This paper assesses the effectiveness of essay tutorials offered to first-year economics students at the UCT (University of Cape Town) in their first language (L1). All students in the study are first-language speakers of an African language. Firstly, using propensity score matching, we econometrically assess the impact of these tutorials on students' essay marks. Although our sample size is small [ $n=220]$, our findings provide preliminary evidence of a positive impact of the intervention on a student's final essay mark. The results show that the average gain for students who attended an essay tutorial in their L1 was $4.85 \%$, with this result being statistically significant at the $10 \%$ significance level. Secondly, students' perceptions of the tutorials' effectiveness, as documented by online evaluations and focus groups, are examined. These findings suggest that allowing for unmediated L1 use in tertiary education classrooms can foster inclusivity and promote participation in otherwise largely monolingual spaces.
\end{abstract}

Keywords: Economics, impact evaluation, language, tertiary education

\section{Introduction}

South Africa's colonial history resulted in the marginalisation of indigenous South African languages ${ }^{1}$ and the disempowerment of their speakers (Alexander, 1999; Kamwangamalu, 2000). For many speakers of African languages at UCT (University of Cape Town), and other historically white institutions, the ramifications of this past persist. The university environment can be alienating and cause students to feel let down by the very education system that ought to be navigating them out of the country's persistent inequality. As noted by Keswell and Poswell (2004), there is robust convexity in the returns to education in South

\footnotetext{
1 In this article, we will refer to South Africa's indigenous languages simply as 'African languages'.

2 Access to the videos is open at http://learnaccounting.uct.ac.za/.

${ }^{3}$ Note that we refer to translanguaging to the extent that it captures the fluid use of language and meaning
} 
Africa, with returns to education exponentially increasing after twelve years of schooling. This has implications for the importance of tertiary education as a means to escape poverty traps (Keswell and Poswell, 2004). However, South Africa's tertiary institutions are at a crossroads: student progress and retention are a major source of concern (Scott, et al., 2007; Heugh, 2013; Kapp and Bangeni, 2017), and important decisions need to be made regarding cultivating and improving inclusivity, and addressing skewed power dynamics (Kapp, 1998; Hurst and Mona, 2017).

South Africa's linguistic diversity is recognised with all eleven official languages being constitutionally equal (Constitution of the Republic of South Africa, 1996: ch1, s6); however, at UCT, along with many other historically-white universities, English remains the dominant medium of instruction and examination (Nudelman, 2015). Results of Rauchas et al. (2006) suggest that students' proficiency in English is the single best predictor of success for firstyear computer science students at a South African university. This points to the importance of being taught in a medium of instruction in which one is proficient, and the authors acknowledge the significant role of language in communicating ideas and concepts (Rauchas, et al., 2006).

Moreover, according to Bhorat et al. (2012), students whose first language (L1) is English have a higher probability of successfully completing tertiary education; yet, only $10 \%$ of students at tertiary institutions in South Africa speak English at home. Thus, a critical problem that we identify in tertiary education currently is that students are keen to explore the new world of knowledge offered at a university but, if prohibited from using the linguistic tools with which they normally express themselves (which could include resources from a number of different African languages), they can effectively feel silenced, impacting both participation in education and subsequent academic outcomes.

In this article, we consider a language-based intervention at UCT, a predominantly monolingual educational space, as an important contributor to improving the academic success of first-language speakers of African languages and promoting more inclusive learning environments in which not only English has currency. The intervention comprises essay tutorials that were offered to first-year economics students in their L1. Introduced in 2017 as part of the School of Economics Writing Programme at the University of Cape Town, the aim of the tutorials was to equip students with knowledge of concepts in their L1 to broaden, clarify and expand their understanding of subject matter. In the past, such language-focused interventions had tended to be placed on the periphery of core activities (UCT, 2003), making the School of Economics' choice to extend support to the mainstream first-year courses especially profound and inclusionary. In this regard, the research questions we aim to address are:

1) whether such language-based interventions have a beneficial impact on academic outcomes in terms of marks, and

2) whether such language-based interventions can assist in fostering inclusivity and promoting participation in largely monolingual spaces. 
Our contribution is to econometrically quantify the impact of the intervention in tertiary education classrooms (an approach currently lacking in South African scholarship on language-based teaching interventions) and provide an analysis of fundamental student insights in this regard.

Whilst tutorials were ultimately multilingual in nature, they were not overtly marketed as multi- or monolingual spaces. This beneficially allowed for the unprescribed and unmediated use of language, and tutors attested to the fact that a mixture of languages were indeed employed in the tutorials. In light of this, in the literature review below we discuss various methods through which non-strict L1 use may emerge in educational spaces.

Scholarship on multilingual methods in education in eastern and southern Africa is well developed across primary, secondary and tertiary education levels (Adendorff, 1996; Rollnick and Rutherford, 1996; Kapp, 1998; Setati and Adler, 2000; Brock-Utne and Holsmardottir, 2004; Dalvit and De Klerk, 2005; Paxton, 2009; Probyn, 2009). Here we simply aim to provide a conceptual and theoretical framework to the reader wishing to understand the manner in which language-based interventions can leverage academic success. Through this we aim to bring coherence to the wide-ranging discourse on multilingual educational practices, with a focus on language practices at UCT providing the background against which the intervention in this study is set.

\section{Literature review}

In 2002, the national Department of Higher Education and Training (DHET) required South African tertiary institutions to develop plans to promote multilingualism and ensure the development of all eleven official languages in academia (Ministry of Education, 2002). This stipulated ' $[t]$ he role of language and access to language skills is critical to ensure the right of individuals to realise their full potential to participate in and contribute to the social, cultural, intellectual, economic and political life of South African society' (Ministry of Education, 2002: 4). In response, UCT developed a multilingualism plan, which recognises the positive and constructive effects of promoting multilingualism across institutional policies and practices (UCT, 2003). It acknowledges that the L1 is an important resource for the development of a second language, that language is a tool for learning and not just communication, and that although performance cannot be attributed solely to language, the university envisages 'the development of multi-media, self-access multilingual materials for key first-year courses' (UCT, 2003: 5).

In this vein, Madiba (2010a) notes that following the increase in the number of students and staff at UCT for whom English is not their L1, an English-only policy can no longer be feasible or adequate in the university environment. Moreover, not all students arrive at university with the same proficiency in English, due to unequal access to English in their schooling. This can result in lower confidence, participation and academic success (Hurst and Mona, 2017).

In providing a detailed review of language policies and practices at UCT, Madiba 
(2010a) highlights notions expressed by students in the institutional climate survey (Smith, et al., 2004) that non-first-language English speakers find it difficult to follow lectures, communicate fully with lecturers and understand exam questions. Kapp and Bangeni (2017), enquiring further into the difficulties non-first-language speakers of English face at UCT, report that students feel silenced by the level and speed at which English is spoken in lectures and highlight students' feelings about not being able to speak their own languages easily in the UCT environment (Kapp and Bangeni, 2017).

Kapp and Bangeni (2017: 88) go on to acknowledge that as their student-participants progressed through their university careers they deliberately code-switched between English and their L1 to a greater extent, 'Africanising' their English. But despite manipulating language in order to stay afloat in the sea of academic work, the authors acknowledge that if students want to succeed, they still 'need to subscribe to the ... circumscribed range of subject positions made available within discourses of the academy' (Kapp and Bangeni, 2017: 93). We argue this linguistic circumscription leads to an apathy towards looking inwards to find their own responses, unmediated by translation, to academic questions.

In 2007, the Multilingual Glossaries Project was launched as one of UCT's strategies to implement its language policy across various disciplines (Madiba, 2010b: 228). In 2009, Paxton wrote about the positive findings of an extension of this project in UCT's School of Economics. The aim of the project was to provide multilingual economics students with the means to broaden and enrich their understanding via concept descriptions in the L1, and by employing a Xhosa-speaking tutor to explain the new concepts (Xhosa being the dominant African language at UCT). Paxton discovered that students tended to rote learn when they did not understand a concept, but if the same concept was explained in Xhosa, they not only understood more but also were able to retain the new information (Paxton, 2009).

In a similar effort, the College of Accounting provided self-access learning resources on its website in the form of short concept videos, which can be played in English, Xhosa, Zulu, Sotho or Tsonga. ${ }^{2}$ In 2017 Jacqui Kew, a professor in the College of Accounting and coordinator of the videos, confirmed the college had tracked approximately 119000 video views on the site since July 2015 , across more than fifteen tertiary institutions. At the time approximately 10000 video views per month were recorded (during university terms).

There are several channels, or multilingual processes, through which the benefits of such language-based interventions may arise in practice. Additive bilingualism, a process through which competence in a second language is gained whilst the L1 is simultaneously maintained (Luckett, 1993), provides one such example. Additive bilingualism is based on the assumption that skills and knowledge obtained in the L1 are easily transferred to another (Luckett, 1993). It suggests that students are first taught concepts via the language in which they are most proficient, and once grasped, understanding is transferred to the second language.

2 Access to the videos is open at http://learnaccounting.uct.ac.za/. 
Another common practice is codeswitching. Codeswitching is an umbrella term given to the process in which individuals use resources from more than one named language and shift between these languages in context (García, 2013). It can be seen as a means of attaining additive bilingualism (Paxton, 2009) because, as Setati and Adler (2000) find, it allows students to harness their $\mathrm{L} 1$ as a learning resource.

Although codeswitching discourses can provide a useful clarifying resource (Ferguson, 2003), García (2013) argues that attempting to give two or more languages a defined role to play, one that keeps them strictly separate (e.g. as codeswitching labels them), is to ignore the far more fluid complexities of languages employed. It is to assume that different languages are used in different domains and for different functions (García, 2013). García (2013) thus advocates instead for the practice of translanguaging, which she situates within the context of multilingualism describing it as a process in which bilingual or multilingual individuals engage in a complex exchange which transcends the linguistic norms established by those in power.

Such practices are exemplified by statements like this one heard on Xhosa radio, Umhlobo Wenene: 'Andifuni a-hurt-ish-ek-e' [I don't want her to go into the state of being emotionally hurt]. The concept of being emotionally hurt is served by the English 'hurt' but the metastative potential extension -ek- denotes 'moving into a state' and is far more economical in Xhosa than in English.

Otheguy et al. (2015: 283) thus describe translanguaging as a person's 'full linguistic repertoire without regard for watchful adherence to the socially and politically defined boundaries of named (and usually national and state) languages'. This definition is especially germane to university domains since students bring with them a wide range of linguistic competencies.

Whilst the concept of translanguaging has gained some traction in debates about language in South African township schools (Sefotho and Makalela, 2017; Dowling and Krause, 2018), it has yet to be fully explored and evaluated in the context of tertiary education. Although we explore the outcomes of an first-language intervention when language use is unmediated - rather than attempting to define a dominant multilingual practice through which benefits accrue - the concept of translanguaging is well suited as a theoretical framework for this study since it promotes multilingual education practice not as a prescribed choice between English and an African language (Heugh, 2002: 193), but as both. ${ }^{3}$

Hurst and Mona (2017) call for translanguaging as a 'socially just pedagogy' and draw on data from a project entitled 'Texts in the Humanities', which is described as a first-yearlevel course for extended degree students in UCT's humanities faculty. This course includes concept glossaries, translanguaging in lectures, tutorials and online forums, as well as essays submitted in any language. Hurst and Mona are lecturers on this course and offer

\footnotetext{
${ }^{3}$ Note that we refer to translanguaging to the extent that it captures the fluid use of language and meaning making, but Garcia and Wei (2014) describe translanguaging as different modalities.
} 
reflections on these pedagogic approaches. The authors find that even though English remains the main language of the lecture theatre, students participate more freely in a translingual style of learning, since they become empowered when their linguistic resources are legitimised and valued, and they feel they can take ownership of the space they are in (Hurst and Mona, 2017).

These sentiments regarding student ownership and empowerment are echoed in dialogue on the use of multilingual glossaries in tertiary education. Despite Paxton's (2009) multilingual glossary for economics students at UCT being received very positively when it was introduced, its use in mainstream economics teaching structures nearly ten years later is limited. We consequently argue that the relevance in Paxton's (2009) findings on the positive response to a multilingual glossary for Economics is not in the existence of the glossary per se, but rather how it points to the importance of students with an African language as an L1 being empowered to use a range of languages and discourses to negotiate their understanding of concepts, thereby improving their epistemological access. Madiba (2010a) acknowledges the value of multilingual tutors in effectively facilitating this process. Simply allowing the student access to a new lexical item will not give them access to how it is used within a specialised domain (Gough, 1999).

In this vein, Madiba (2010b) argues that dictionary definitions give learners a superficial understanding and encourage the very rote learning that multilingual practices aim to overcome. Accordingly, he advocates corpus-based multilingual glossaries which make use of contextual examples to overcome conceptual difficulties. This ties in with Mesthrie's (2008: 337) argument that although he does not dispute that all languages have the ability to take on an academic register, the creation of glossaries and word lists is a complicated task that will not necessarily result in the desired goal of 'inculcating multilingualism'. He claims glossaries cannot take the place of students actually using academic lexicons and discourses meaningfully and argues that meaning should rather be negotiated 'within an appropriate community of practice' (Mesthrie, 2008: 337). This community of practice allows students, for example, to use the word i-deficit (Paxton, 2009: 353 ) in context, using familiar morphology from their own language ( $i$ - in the case of $i$-deficit) and a new lexical item ('deficit'), simultaneously disproving the presumption that terms available in English cannot be available to the African language.

However, despite the introduction of a variety of language-based interventions at UCT, there remains a case for greater scope of such programs. It appears especially that there is room for a greater impetus to institute more regular classroom exchanges in students' languages of choice, that goes beyond the creation of concept glossaries only in the L1. Providing a meaning for a concept that allows students to translanguage, for example, makes it more likely that they will create a personal reconstruction that they can remember. Such classroom practices can then be harnessed to improve upon such multilingual glossaries and create new ones where appropriate.

We furthermore identify a considerable gap in the literature on quantifying the outcomes of such interventions. Evaluations are confined either to qualitative analyses or 
descriptive statistics without rigorous quantitative analyses which attempt to identify significant association between the intervention and its outcomes. We thus make a contribution to the discourse on language-based interventions in this regard, and by situating our qualitative analysis in the framework of translanguaging, aim to add meaningful dialogue on the value of leveraging fluid, unmediated language use in tertiary education teaching and learning.

\section{Methodology}

The focus of this study is the language-based essay tutorials that were introduced in 2017 as part of the School of Economics Writing Programme at the University of Cape Town, for the DHET-funded project 'Embedding Academic Literacies in the Faculty of Commerce'. The aim of the tutorials was to equip students who are not first-language speakers of English with knowledge of concepts in their L1 to broaden, clarify and expand their understanding of subject matter.

Tutorials were offered in Xhosa, Zulu and $\mathrm{Pedi}^{4}$ to first-year students in the first semester. In the second semester, tutorials were offered in Xhosa and Zulu. The languages chosen were based on data about the L1 of the first-year students and the availability of markers (also essay tutors) who could speak the languages and were willing and able to conduct a tutorial in them. Notwithstanding the title of the tutorials as named languages, language use within the tutorials was unprescribed and unmediated.

Across both semesters twenty-six students attended an essay tutorial in Xhosa and seven attended a tutorial in Zulu. One student attended the Pedi tutorial offered in the first semester. This represents resource uptake rates of $25 \%$ for the Xhosa tutorials, $9 \%$ for the Zulu tutorials, and $7 \%$ for the Pedi tutorial. ${ }^{5}$ A limitation in the study design is that it relied on a second party, namely the essay tutors, to capture information on tutorial attendance. The number of attendees recorded for Zulu tutorials is likely to be understated on account of the fact that only one of the four tutorial registers issued in the first semester was returned by the tutor for capturing.

Data were collected in both semesters to examine the effectiveness of the tutorials. These data were obtained through tutorial attendance registers, which served as an indicator of resource uptake, and online evaluations completed by students. Online evaluations assess other essay interventions offered, as well as students' overall perceptions of the essay process, thus all students are eligible to complete an evaluation, not only those who attended a tutorial. If students did not attend a tutorial, they simply indicate a reason for why they chose not to attend. Of the thirty-four students who attended an essay tutorial offered in an African language in 2017, eight - all of whom attended a tutorial in Xhosa - completed an

\footnotetext{
4 The student capacity for the tutorials offered in African languages stood at 150 students: 105 for Xhosa (seven tutorials offered), 75 for Zulu (five tutorials offered) and 15 for Pedi (one tutorial offered, in first semester only).

5 Uptake rates are calculated as a proportion of total capacity as listed in footnote 5 above.
} 
online evaluation. Another 186 students who did not identify English as their L1 and did not attend a tutorial in an African language, also completed the evaluation.

The online evaluations, besides collecting students' personal information, facilitate important insights in two ways. Firstly, they provide us with student perceptions regarding the quality of the intervention and whether they found the essay tutorial beneficial or not with respect to their academic writing $(n=8)$. Secondly, they allow us to identify students who identify as non-English speakers, but who did not attend an African language tutorial ( $n=186$ ). Because we know which African language speakers used the resource (from the attendance registers, $n=34$ ), and which did not (from the online questionnaire, $n=186$ ), we are able to comment on the effectiveness of the essay tutorials through an econometric assessment of their 'treatment effect' $(n=220)$. The 'treatment effect' refers to the causal effect of a binary (0-1) variable on an outcome variable. In the context of the present study, we seek to explore the impact of attending an essay tutorial in the L1 on the outcome variable of students' essay results. All the students in the study have an African language as their L1.

However, the principal econometric problem entailed in in the estimation of treatment effects is selection bias. Selection bias arises from the fact that treated individuals differ from the non-treated for reasons other than treatment status per se (Wooldridge, 2010). For example, students who have a particular interest in economics or essay writing, and who may inherently work harder for this reason, may also have been more likely to participate in the intervention. In order to mitigate the selection bias inherent in our use of observational data collected during 2017 , the analysis of the treatment effects of each intervention is done using propensity score matching.

PSM (propensity score matching) is a statistical matching technique that estimates the effect of a treatment by accounting for the covariates that predict receiving the treatment (Wooldridge, 2010). The underlying idea of matching is straightforward: in the absence of an experimental design, assignment to treatment (in this case, attending an African language essay tutorial) is not done at random. This allows for people receiving treatment, and those excluded from treatment, to differ not only in their treatment status, but also in terms of other attributes that influence both their decision to participate and the outcome of interest (Wooldridge, 2010). To avoid the biases that this may generate, matching methods find a non-treated unit that is 'similar' to a participating unit, allowing an estimate of the intervention's impact as the difference between a participant and the matched comparison case (Wooldridge, 2010). Averaging across all participants, the method provides an estimate of the mean programme impact for the participants.

For the students in our sample, we were able to obtain the data for the following variables that could control for the selection bias: students' gender, matric English mark, and National Benchmark Test $^{6}$ (NBT) scores, and whether or not the student was taking

6 The National Benchmark Tests measure academic readiness for university. See https://nbt.ac.za/content/faq. 
economics as a major or an elective. We also control for students' use of any of the other support services offered as part of the writing programme, all of which were conducted in English. This is to ensure that we adequately account for the fact that students' writing may have been influenced by support received through an English-based (as opposed to African language) intervention. These data come from the attendance registers for these resources.

Endogeneity arises in cases where we believe there is some unobservable factor affecting both treatment participation (choosing to attend an essay tutorial in an African language) and the potential outcome (essay result). It is reasonable to assume, for example, that if a student has a part-time job, this could influence their decision whether or not to participate in an intervention (their work schedule may not allow them to attend a tutorial in the afternoon), as well as their essay marks (the part-time job may leave less time for academic commitments). We do not have data on this factor and therefore cannot control for it.

Consequently, the results produced using the propensity matching techniques must be interpreted in light of the fact that we may not be controlling for endogeneity, which has implications for the consistency of our estimates. A further limitation of this analysis is that when the online evaluation was designed and implemented, it was done so as an internal monitoring and evaluation tool only. Findings are thus constrained by evaluation uptake and design.

We supplement our quantitative analysis on the academic outcomes of leveraging language, with data collected through two focus groups held at the end of the second semester. These focus groups involved discussions about the role of language in the classroom, attitudes to language, language preferences and the actual experience of the tutorials in African languages. The focus groups consisted of two tutors (one first-language Xhosa speaking and the other first-language Zulu speaking, but who is able to speak Sotho as well) who ran the essay tutorials in question, and four first-year economics students who were first-language speakers of African languages. Whilst these four students did not attend an essay tutorial in their L1 and could not offer insights on actual participation in the language tutorials, they did provide information about language attitudes and ideas for future improvements in multilingual tutorial support. They cited tutorial clashes as the reason they could not attend the tutorials in African languages. Since tutors are also students themselves, their reflections provide insights into student-related views and aspirations as well. All participants gave their consent and the relevant ethical clearance obtained.

\section{Results and Discussion}

\section{Quantitative Results}

Student perceptions of the effectiveness of the Xhosa essay tutorial

Data obtained from the students who attended a Xhosa tutorial and completed the online evaluation show that students perceived the Xhosa tutorials to have been a useful resource in assisting them with their academic writing in English. None of the students disagreed with 
the proposition that the Xhosa tutorial had aided their understanding of the economic concepts, and none of the students who attended the Xhosa essay tutorial left feeling that they did not know what the essay required of them. All eight students who completed the evaluation believed that this type of support should be offered in future. Further evidence in favour of this intervention is the fact that seven out of the eight students indicated that they would recommend this service to a friend whose L1 was not English.

Students were asked to suggest what grade they thought they might receive for the essay without attending the essay tutorial, and what grade they might get after attending it. Prior to attending the tutorial one student expected to fail the essay and no students anticipated a first-class pass (a mark above 75\%). Following the tutorial, all but one student revised their expectations upward, with that one student not expecting their mark range to change. Following the Xhosa tutorial, no student felt as though they were going to fail the essay, and two students adjusted their expectations upwards to reflect the expectation that they would receive a first-class pass.

In the next subsection we present the results of the econometric assessment of the effect of the African language tutorials on students' final marks.

Estimation of treatment effects for attending a tutorial in an African language

There are 220 students in our sample, thirty-four of whom made use of an African-language tutorial, and 186 of whom did not, but do identify an African language as their L1. Our objective is to understand the impact of the African language tutorial system on students' final essay marks. Table 1 presents summary statistics for the key variables used in the analysis.

Table 1: Summary statistics for students who identify an African language as their first language $(n=220)$

\begin{tabular}{|l|c|c|c|c|c|}
\hline Variable & $N$ & MEAN & Std Dev & Min & Max \\
\hline Essay score (\%) & 220 & 59.06 & 12.38 & 20 & 85 \\
\hline Male & 220 & 0.40 & 0.49 & 0 & 1 \\
\hline Major & 220 & 0.49 & 0.50 & 0 & 1 \\
\hline Attended an African language tutorial & 220 & 0.15 & 0.36 & 0 & 1 \\
\hline Used a non-African language essay support intervention & 220 & 0.38 & 0.49 & 0 & 1 \\
\hline NBT quantitative literacy score (\%) & 201 & 61.77 & 16.14 & 33 & 96 \\
\hline NBT mathematics score (\%) & 201 & 56.47 & 17.84 & 0 & 96 \\
\hline NBT academic literacy score (\%) & 201 & 63.73 & 10.34 & 39 & 88 \\
\hline Matric English score (\%) & 193 & 75.80 & 7.93 & 40 & 93 \\
\hline
\end{tabular}


- indicates that the variable is a binary variable that takes on a value of zero or one.

All decimals rounded to two decimal places.

The mean essay score in the sample is approximately $59.06 \%$. The variables 'Major', 'Gender', 'Attended an African language tutorial', and 'Used a non-African language essay support intervention' are binary. As such, the means presented in Table 1 indicate the proportion of observations coded as 1 in each category. For the male variable, being male records a response of unity and being female records a response of zero. Thus, from Table 1 , we know that $40 \%$ of people in the sample are male. Similarly, approximately $49 \%$ are taking economics as a major, and approximately $38 \%$ used a form of essay writing support intervention other than the African language essay tutorial.

Using these data, we estimate the average treatment effects for the African language essay tutorials in Stata version 13. The results of our analysis are presented in Table 2. The average treatment effect (ATE) shows the expected gain from attending a workshop for a randomly selected unit from the population. The average treatment effect of the treated (ATET) shows the average gain from attending a workshop for those who actually attended.

The treatment effects shown in Table 2 make a strong case for the continuation of African language essay tutorials in the School of Economics Writing Programme. The expected gain for attending such a tutorial for a random student who identifies an African language as their $\mathrm{L} 1$ is a $4.01 \%$ increase in their essay result (the ATE), with this finding being statistically significant at the $10 \%$ significance level.

Table 2: Treatment effects of attending an essay tutorial in an African language.

\begin{tabular}{|l|c|}
\hline Treatment effects & Coefficient \\
\hline Average treatment effect (ATE) & $4.01(3.13)^{*}$ \\
\hline Average treatment effect of the treated (ATET) & $4.85(2.53)^{*}$ \\
\hline $\begin{array}{l}\text { Al robust standard errors in parentheses. } \\
\text { * Indicates that the coefficient is statistically significant at the 10\% significance level. } \\
\text { All decimals rounded to two places. }\end{array}$
\end{tabular}

The average gain for students who actually attended an essay tutorial in an African language (ATET) was $4.85 \%$, with this result also being statistically significant at the $10 \%$ significance level. The ATET makes it clear that a large benefit accrued to students who attended an essay tutorial in an African language in terms of their essay marks. This provides compelling evidence that rolling out tutorials in African languages on a greater scale (e.g. across the weekly content tutorials offered to first-year economics students) is likely to bring about significant improvements in marks, especially if the interactions are weekly, and not just one-off occurrences, as is the case with essay tutorials. This corroborates sentiments expressed by Scott et al. (2007) that foundational provision that is aligned with language background can assist students in becoming successful graduates. 


\section{Qualitative Results}

'It's usually a mixture - you just flow with it': Tutors and students discuss language usage In order to gauge everyday language preferences at the outset, we began our focus groups by asking the tutors and students questions about their language practices outside the university. Tutors did not appear to be overtly conscious of when they used English in everyday conversation. As one tutor put it:

It's just a language that is generally accepted that includes all these English words and we are not mindful about that. It's just because they make communication easy and we understand what you are talking about.

About their language practices on social media one tutor remarked: 'It's usually a mixture you just flow with it'.

The most telling comment from this group of tutors about the multilingual tutorials was: 'You shouldn't be discussing about who expresses themselves in what way, you know. I think it should just be about understanding the next person'. Another tutor reflected that after school, university felt 'unrealistic and it's difficult to understand these concepts. It's much better when you have someone to explain in everyday language'. The fact that the tutor did not name the language, but referred to it as 'everyday', is significant. It resonates with the comment above that 'it's usually a mixture - you just flow with it', suggesting that tutors' engagement with language outside the university is a smooth, unmediated negotiation of codes chosen for particular purposes 'without regard for watchful adherence to the socially and politically defined boundaries' of named languages (Otheguy, et al., 2015: 283).

Non-strict first-language practices are further evidenced by answers we received from tutors when we asked them what percentage of tutorials they conducted in English and what percentage in African languages. Their responses indicated that $40-60 \%$ of the tutorials were conducted in African languages, with the remainder in English. One tutor remarked that to achieve this fusion of languages, he would 'take English words and Xhosify' them. Wells (1999) emphasises that in this way students use what they already know to construct their own understanding of new information that they are presented with, creating a 'personal reconstruction' which reflects appropriation of meaning formed on a transformed understanding.

Thus the tutor's observation about his language use in the tutorial hints at the fact that unprescribed and unmediated language use in an first-language setting allows the tutor agency to use familiar linguistic resources to illuminate concepts (especially the semantics of African language morphology) that he might otherwise struggle to convey (see Dowling and Krause, 2018). Providing commentary on translanguaging, Dowling and Krause (2018: 3) perceive how this freedom from linguistic restriction can allow the grammar of a language (as well as its lexicon) can be used to students' advantage by forming an integral part of their 
linguistic 'toolkit' with which they can learn not only subject specific discourses, but also a target language which may not yet be fully developed.

We discovered that students struggle to understand concepts in English mainly because they do not fully understand the kind of language used in discussing these concepts. A student participant confirms how learning a concept in their L1 assists with retention:

If there is somewhere where you can watch it in your own language you can see, 'Okay, this is what they mean, this is how you apply it'. So it makes understanding the concept in English more easy ... It would be easy for you to grasp the content and you will never forget.

Another student endorses this:

I feel like I remember a lot of things when they are in vernac [vernacular language] more than in English. Like I would be like, 'Okay, ndiyakuva [I hear you],' and I would literally understand, I would memorise more if it was in Xhosa.

'Normalising my own language': Tutors and students discuss inclusivity and comfort A tutor expanded on the call for translingual spaces, remarking that such spaces afford students the opportunity to express themselves comfortably and not be afraid of asking 'stupid questions'. He felt that in these spaces, 'they were more comfortable and flowing and they asked more questions'.

These affirmative sentiments towards discussion in the vernacular were corroborated by the second tutor, who said that had he been able to attend such a tutorial in his first year, he would have felt more relaxed about expressing his views on an academic topic.

A student acknowledged her many language resources, and the flexibility with which she used them, but found assurance in the language in which she was most comfortable, adding that her English 'runs away at times':

Yho, I'm from Joburg. So, like, I'm very flexible. I speak any language. But then my first preference is probably what am better at, which is Zulu and a bit of Sotho and maybe Xhosa.

She also believed that attending a tutorial in her language of choice would make her feel more comfortable in the university environment, since, coming from a rural school, she would prefer not to have to switch to English immediately and exclusively. Another student echoed this reluctance to abandon the $L 1$ and indirectly accused the university of destabilising it, suggesting that she would welcome a situation in which it could just be seen as normal to use one's L1: 'Normalising my own language maybe? ... Like making it normal, like it's normal for you to speak your language and writing your own language'. 
'What would intimidate me would be strong Xhosa words that I don't understand': Tutors and students discuss 'othering' and purist notions

Despite the positive reflections described above, students indicated that they would not choose a full curriculum in their L1, preferring English lectures and assessments with additional support in African languages (here pointing us to the videos created by UCT's College of Accounting as a supplementary study resource) because:

It [English] is something that when I get out of University, I should be more skilful in, you know. ... some concepts are not easy to explain in Xhosa and some concepts you cannot get when you explain in Xhosa, so like it would be helpful if we have that option whereby if you decide that okay, now we need it in Xhosa - we can do this, and okay, Xhosa cannot go to a certain extent. You know, economics is very crazy.

Students at the University of Fort Hare, in the predominantly Xhosa-speaking Eastern Cape, also felt that Xhosa as a medium of instruction would only be useful if nuanced options were introduced that did not necessitate an absolute choice between English and Xhosa (Dalvit and De Klerk, 2009). ${ }^{7}$ In a similar vein, a tutor in our study revealed that students would email him questions in English which he would reply to with a breakdown of the topic and concepts in Zulu. It would appear, then, that neither students nor tutors want to create conditions in which one language dominates.

These insights corroborate suggestions from tutors that if spaces were created in which only Xhosa, Zulu or other named languages could be used, the users of those spaces might end up feeling negatively branded as coming from 'outside' - and 'people don't want to come out as that'. This points towards what García (2013) describes as the 'othering' imposed by bilingual practices such as codeswitching.

Attending language-based intervention that does not accommodate unmediated use of language (e.g. translanguaging) could thus be off-putting to students on two levels, namely: 1) the 'othering' that may come from seeking assistance in their $L 1$, and 2) the fear of not being competent enough in the L1. Allowing for a more translingual approach eliminates the linguistic compartmentalisation (and inevitable othering) perpetuated by purist notions of language.

Students should never be made to feel as if their way of using language is inferior because it is not 'proper' or 'real', or that they need a certain proficiency or 'level' to benefit from tuition. Rather, spaces need to be created in which students' everyday language is given credibility and valorised, and in which students and tutors are not intimidated by language, whether it be English or their L1. This ensures students are not exiled from their language, whilst supressing the perpetuation of colonial constructs of language.

\footnotetext{
7 Dalvit and De Klerk (2009) suggest that this is probably due to English prevailing as the language of the middleclass and one that affords better employment opportunities.
} 


\section{Conclusion}

Preliminary insights offered by this study suggest that leveraging language-based interventions that allow for the unprescribed and unmediated use of language helps students see the way they normally speak and write not only as legitimate, but also as a source of insights into academic concepts. This cultivates more inclusive learning environments in which students are empowered to participate. Quantitative findings suggest this linguistic empowerment translates to practically and statistically significant academic empowerment of students too.

This study provides compelling evidence to roll out similar language-based interventions on a broader - and potentially more regular - scale, as well as points to the fact that there remains as great a need as ever to align our educational processes to meet the diverse linguistic resources of the student body. But we argue that if the aim of such practices is to allow students whose L1 is not English the opportunity to navigate concepts in their L1 as well as in English (Paxton, 2009), while not aggravating stigmas or divisions, future tutorials or other language-based interventions should be designed and branded in such a way as to encourage students and tutors to fluidly choose from and employ all familiar linguistic competencies available to them. This will allow students to understand subject content more readily without abandoning the English resources through which they will ultimately need to demonstrate their academic understanding (Dowling and Krause, 2018).

However, as Hurst and Mona (2017) argue, implementing such interventions in isolation is unlikely to have the desired level of impact that such pedagogies have the power to create. Therefore, we argue that the success of language-based interventions in South Africa must arise through sustained commitment across higher education institutions to widely adopt, as a point of leverage, teaching and learning practices that employ language as a powerful tool, and an undoubtedly indispensable medium for knowledge and information.

\section{Limitations and future research}

Whilst tutorials were ultimately multilingual in nature, they were not overtly marketed as multi- or monolingual spaces. This beneficially allowed for the unmediated use of language. Nonetheless, as we previously acknowledge, students are potentially apprehensive about lacking proficiency in their $\mathrm{L} 1$, this being perpetuated by purist ideologies. A lack of marketing about the nature of language use expected may have impacted attendance via this channel. We were also obliged to hold the focus groups while protests were occurring on the UCT campus and believe that this affected attendance.

The sample size of this study is limited and constrained by the nature of data collection instruments, which were designed and implemented prior to the formalisation of the quantitative aspect of this study. Thus, more research is needed on this topic to avoid the premature extrapolation of results. 
For these reasons, as well as the need to deepen scholarship in this area, we call for further research - both qualitative research and quantitative impact evaluation - on subsequent enactments of using language as a learning resource. Of particular interest would be an analysis of the effect of more frequent unmediated classroom engagement in the L1 on test and examination marks. If this can occur across departments and institutions, this will constructively strengthen the external validity of these findings.

\section{Author Biographies}

Emma Whitelaw holds an MSc in Economic and Public Policy from the University of York and an MA in African Languages and Literatures from the University of Cape Town. She is currently based in the School of Economics at the University of Cape Town, where her research is broadly focussed on post-schooling education in South Africa.

Samantha Filby is a research officer and lecturer in the School of Economics at the University of Cape Town. Her current research focuses on the economics of health taxation. She holds a Masters degree (cum laude) specializing in Economic Development from the University of Cape Town.

Tessa Dowling has a PhD in African Languages from the University of Cape Town, where she is a senior lecturer in African Languages. She is an active researcher, particularly in the field of African languages in the media and language change in Xhosa. Her more recent publications include: "Language Contact in Cape Town", co-authored with Kay McCormick and Charlyn Dyers in in English in Multilingual South Africa, edited by Raymond Hickey, Cambridge University Press (2019) pp.129-150; Problems in the acquisition of Noun Class 11 among Xhosa children", co-authored with Derek Gowlett - Southern African Linguistics and Applied Language Studies (2016) 34(4):289-309; "Ndifuna imeaning yakhe': translingual morphology in English teaching in a South African township classroom", coauthored with Lara Krause - International Journal of Multilingualism (2018) DOI: 10.1080/14790718.2017.1419475; "Working towards culturally and linguistically diverse speech assessments for South African children: A Xhosa case study", co-authored with Emma Whitelaw - Language Matters (2018) 49(2):39-61.

\section{References}

Adendorff, R.D. 1996. The functions of code switching among high school teachers and students in Kwazulu and implications for teacher education. In Bailey, K.M. \& Nunan, $D$. (eds) Voices from the language classroom: Qualitative research in second language education. Cambridge, UK: Cambridge University Press, 338-406.

Alexander, N. 1999. An African renaissance without African languages? Social Dynamics, 25(1): 1-12, DOI: 10.1080/02533959908458658. 
Bhorat, H., Mayet, N. \& Visser, M. 2012. Student Graduation, Labour Market Destinations and Employment Earnings. DPRU Working Paper 12/153. Cape Town: Development Policy Research Unit.

Brock-Utne, B. \& Holsmardottir. H. B. 2004. Language policies and practices in Tanzania and South Africa: Problems and challenges. International Journal of Educational Development, 24: 67-83.

Constitution of the Republic of South Africa, 1996. Available at: http://www.justice.gov.za/legislation/constitution/chp01.html (accessed 3 February 2018).

Dalvit, L. \& de Klerk, V. 2005. Attitudes of Xhosa-speaking students at the University of Fort Hare towards the use of Xhosa as a language of learning and teaching (LOLT). Southern African Linguistics and Applied Language Studies, 23(1): 1-18.

Dowling, T. \& Krause, L. 2018. 'Ndifuna imeaning yakhe': Translingual morphology in English teaching in a South African township classroom. International Journal of Multilingualism, DOI:10.1080/14790718.2017.1419475.

García, O. \& Wei, L. 2014. Translanguaging: Language, Bilingualism and Education. Basingstoke, U.K.

García, O. 2013. From Diglossia to Transglossia: Bilingual and multilingual classrooms in the 21st century. In Abello-Contesse, C., Chandler, P.M., López-Jiménez, M.D. \& ChacónBeltrán, R. (eds.) Bilingual and Multilingual Education in the 21st Century: Building on Experience. Bristol: Multilingual Matters, 155-178.

Gough, D. 1999. African languages: Discourse, concepts, education and other challenges. In Prah, K.K. (ed.) Knowledge in Black and White: The Impact of Apartheid on the Production and Reproduction of Knowledge. Cape Town: Centre for African Studies, 169-77.

Heugh, K. 2002. The Case against bilingual and multilingual education in South Africa: Laying bare the myths. Perspectives in Education, 20(1): 171-196.

Heugh, K. 2013. Multilingual education policy in South Africa constrained by theoretical and historical disconnections. Annual Review of Applied Linguistics, 33: 215-237.

Hurst, E. \& Mona, M. 2017. 'Translanguaging' as a socially just pedagogy. Education as Change, 21(2): 126-148.

Kamwangamalu, N. M. 2000. A new language policy, old language practices: Status planning for African languages in a multilingual South Africa. South African Journal of African Languages, 20(1): 50-60.

Kapp, R. 1998. Language, culture and politics: The case for multilingualism in tutorials. In Angelil-Carter, S. (ed.) Access to Success: Literacy in Academic Contexts. Cape Town: University of Cape Town Press, 21-34.

Kapp, R. \& Bangeni, B. 2017. Negotiating Learning and Identity in Higher Education: Access, Persistence and Retention. London: Bloomsbury. 
Keswell, M. \& Poswell, L. 2004. Returns to education in South Africa: A retrospective sensitivity analysis of the available evidence. South African Journal of Economics, 72(4): 834-860.

Luckett, K. 1993. National additive bilingualism: Towards the formulation of a language plan for South African schools. Southern African Journal of Applied Linguistic Studies, 2(1): 38-60.

Madiba, M. 2010a. Towards multilingual higher education in South Africa: The University of Cape Town's experience. Language Learning Journal, 38(3): 327-346.

Madiba, M. 2010b. Fast-tracking concept learning to English as an additional language (EAL) students through corpus-based multilingual glossaries. Alternation, 17(1): 225248.

Mesthrie, R. 2008. Necessary versus sufficient conditions for using new languages in South African higher education: A Linguistic Appraisal. Journal of Multilingual and Multicultural Development, 29(4): 325-340.

Ministry of Education. 2002. Language Policy for Higher Education. Pretoria: Ministry of Education. Available at:

http://www.dhet.gov.za/Policy\%20and\%20Development\%20Support/Language\%20Pol icy\%20for\%20Higher\%20Education_2002.pdf (accessed 3 February 2018).

Nudelman, C. 2015. Language in South Africa's higher education transformation: A study of language policies at four universities. Unpublished MPhil Thesis, University of Cape Town, South Africa.

Otheguy, R., García, O. \& Reid, W. 2015. Clarifying translanguaging and deconstructing named languages: A perspective from linguistics. Applied Linguistics Review, 6(3): 281-307.

Paxton, M. 2009. 'It's easy to learn when you using your home language but with English you need to start learning language before you get to the concept': Bilingual concept development in an English medium university in South Africa. Journal of Multilingual and Multicultural Development, 30(4): 345-359, DOI:10.1080/01434630902780731.

Probyn, M. 2009. 'Smuggling the vernacular into the classroom': Conflicts and tensions in classroom codeswitching in township/rural schools in South Africa. International Journal of Bilingual Education and Bilingualism, 12(2): 123-136.

Rauchas, S., Rosman, B., Konidaris, G. \& Sanders, I. 2006. Language performance at high school and success in first year computer science. ACM SIGCSE Bulletin, 38(1): 398402.

Rollnick, M. \& Rutherford, M. 1996. The use of mother tongue and English in the learning and expression of science concepts: A classroom-based study. International Journal of Science Education, 18(1): 91-103.

Scott, I., Yeld, N. \& Hendry, J. 2007. A Case for Improving Teaching and Learning in South African Higher Education. Higher Education Monitor 6. Pretoria: Council on Higher Education. 
Sefotho, M.P. \& Makalela, L. 2017. Translanguaging and orthographic harmonisation: A cross-lingual reading literacy in a Johannesburg school. Southern African Linguistics and Applied Language Studies, 35(1): 41-51.

Setati, M. \& Adler, J. 2000. Between languages and discourses: Language practices in primary multilingual mathematics classrooms in South Africa. Educational Studies in Mathematics, 43(3): 243-269.

Smith, M. J., Dube, N., Gasnola, S. \& Myeza, M. 2004. Same River, Different Boats: Report on 13 Focus Groups with UCT Students. Unpublished.

UCT. 2003. A Language Plan for the University of Cape Town: 2005-2010. Cape Town: University of Cape Town. Available at: http://www.mep.uct.ac.za/usr/mep/ downloads/languageplan.pdf (accessed 3 February 2018).

Wells, G. 1999. Dialogic Inquiry: Towards a Sociocultural Practice and Theory of Education. Cambridge: Cambridge University Press.

Wooldridge, J. M. 2010. Introductory Econometrics: A Modern Approach. 5th edition. Massachusetts: Cengage Learning. 